\title{
Challenges related to flotation cleaning of oil shales. Issues due to compositional and surface features and post-grinding surface behavior
}

\author{
N. Emre Altun ${ }^{1, a}$ \\ ${ }^{1}$ Midlle East Technical University, Mining Engineering Department, Ankara, Turkey
}

\begin{abstract}
Oil shale is an important energy resource alternative. Despite its recognition as an unconventional oil source, oil shale is also considered as an important solid fossil fuel alternative to coal and lignites due to the solid form and remarkable extent of organic content. Utilization possibilites, similar to coal and lignites, have been considered in the past decades and direct use of oil shales in thermal power production has been possible in countries like Estonia and China. In the perspective of utilization of oil shales in a similar manner to coal and lignites, problems and restrictions related to the inorganic ash-making and potentially pollutant constituents are applied. In this respect, cleaning of this important energy source through mineral processing methods, particularly by flotation, is an outstanding option. However, on the basis of unique features and distinctive characteristics, treatment of oil shales like a type of coal is a big perception and may be highly misleading. This paper discusses specific challenges regarding flotation behavior of oil shales with reference to the surface characteristics and behavior of oil shale entities - probably the most important aspect that determines the efficiency and success of the flotation based cleaning process.
\end{abstract}

\section{Introduction}

Energy supply is still a major issue for human civilization. Increasing demand for energy in the globe necessitates evaluation and usage of various alternative sources. Despite efforts towards utilization of renewables, non-renewable solid fossil fuels are still an outstanding energy resource. On accounts of factors such as secure supply, lower costs of utilization and extensive and well-dispersed reserves in many countries, not only coal, but other solid fossil fuel reserves, become even more important. Among alternatives to coal and lignite, oil shale is probably the most important solid fossil fuel option, with huge reserves, a variety of utilization possibilities and beneficiation routes similar to those applied to coal and lignites.

The type of organic matter in oil shales consists mainly of kerogen and with lower amounts bitumen. In this respect, oil shales have been treated as an unconventional oil source $[1,2]$. However, being solid and having a combustible potential, using oil shales as a solid fuel substitute is also a known practice. Estonia is particularly an outstanding example for such a practice and in use of oil shales in thermal power production, similar to coal and lignite usage [3]. Considering oil shales as an

${ }^{a}$ Corresponding author: ealtun@metu.edu.tr 
alternative solid fossil fuel rather than an unconventional oil source introduces envrionmental restrictions, which apply to utilization of coal such as ash, post-combustion gases, etc.

Despite the possibility of application of cleaning methods such as flotation and/or gravity concentration techniques, oil shales possess extremely specific characteristics based on their origin, formation and occurrence. These critical differences, related to the surface behavior and/or type of organic matter, require a comprehensive evaluation of the physical, chemical and physicochemical characteristics of oil shales prior to establishing a utilization route.

This paper specifically discusses distinctive surface characteristics of oil shales, both in their original forms as well as after grinding, as a primary step before further physical/physicochemical processes that could be applied. The objective is also to assess these distinctive features as an explanation to some of the critical challenges during flotation cleaning of oil shales to reduce the amount of ash making and potentially pollutant constituents, related to use of oil shales as a substitute to coal and lignites.

\section{Issues related to composition and surface characteristics of oil shales}

Figure 1 and 2 show XRD spectra of a high and low quality oil shale samples from Turkey, respectively $[4,5]$. The spectra show that oil shales may consist of variety of inorganic minerals, i.e. ash making components as well as those resulting in harmful post-combustion emissions. All these inorganic minerals, typical for almost any oil shale deposit, show the potential and necessity for application of mineral processing methods for cleaning of oil shales, i.e. rejection of inorganic constituents to achieve a cleaner and environmentally sound enery resource alternative. In addition, remarkable extent of sulfur involving constituents such as pyrite in oil shales point to the requirement of cleaning procedures to avoid/decrease post-combustion $\mathrm{SO}_{2}$ emissions. It should be noted that, despite the presence of a variety of minerals, the inorganic matter in oil shales is dominated by carbonate minerals, i.e. calcite and dolomite, with calcite being the major carbonate. As opposed to many types and particularly low-ranking coals, the organic matter is abundant in oil shales, especially in those with lower quality.

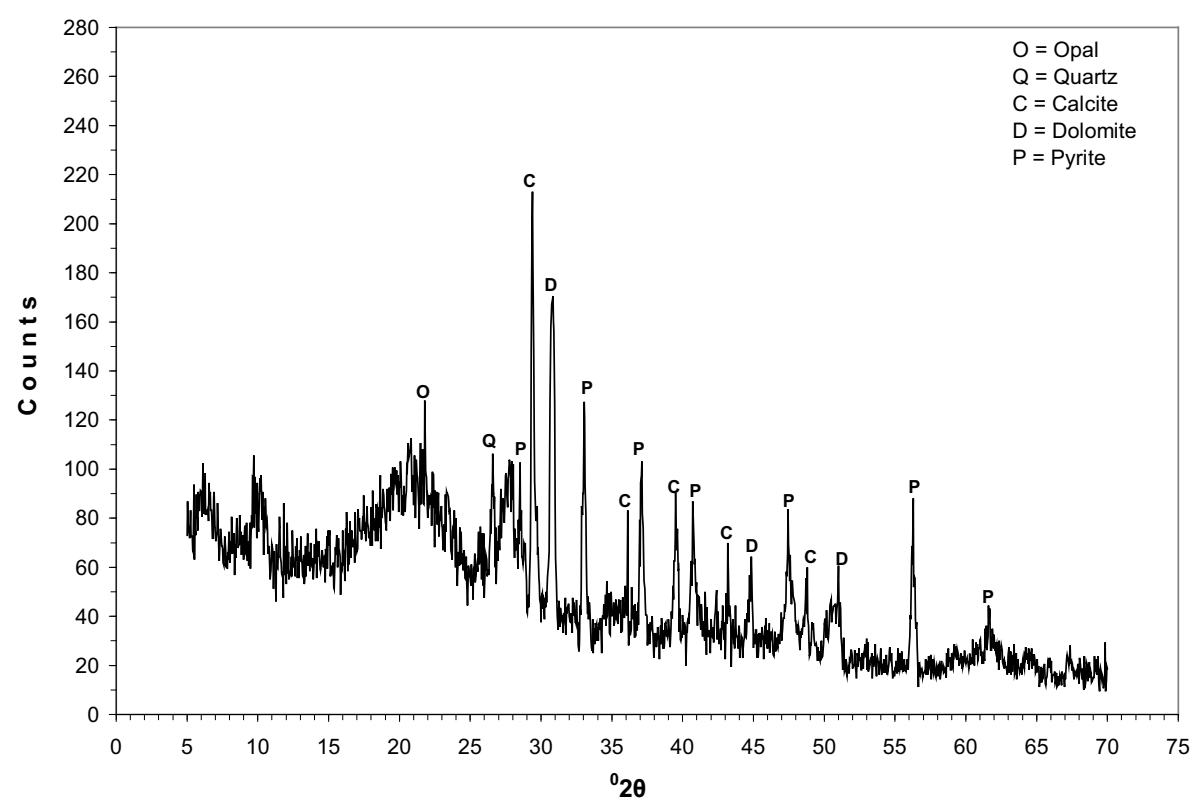

Figure 1. XRD spectrum of a high-quality oil shale [4]. 


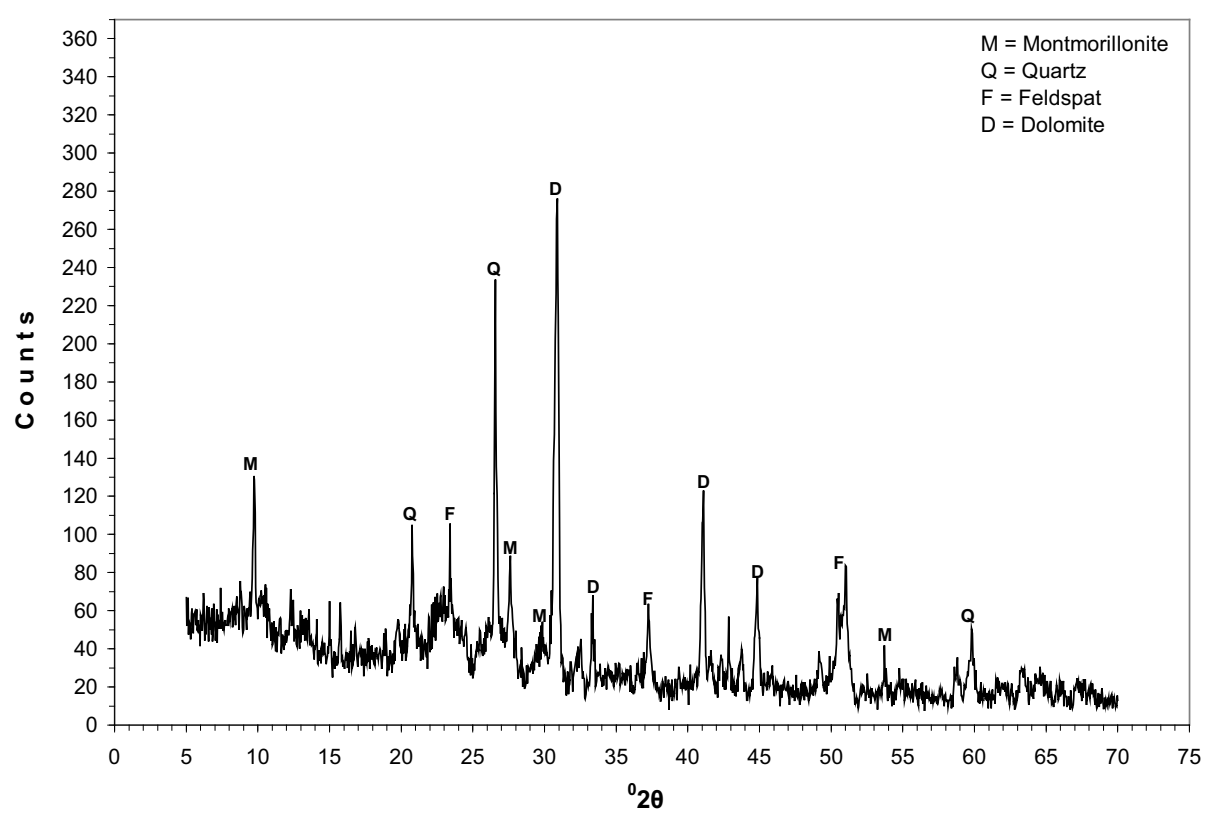

Figure 2. XRD spectrum of a low-quality oil shale [5].

The relative abundance of inorganic matter and carbonates is a remarkable challenge in application of flotation as oil shales cleaning [4, 5]. In direct flotation, high extent of the inorganic matter in the pulp presents a challenge against the bubble-organic matter interaction. The smears of organics on the surfaces increases the possibility of entrapment and eventually causies dilution of the organic-rich concentrate. All these factors reduce the efficiency and effectiveness of oil shale cleaning using the direct flotation process. The results of such challenges and the insufficient cleaning of oil in some details in the previous studies shales using direct flotation were well expressed in some details in previous studies $[4,5]$.

The surface features of oil shale particles is another major challenge in flotation cleaning of oil shales. Figure 3 shows the FTIR spectra of a high-quality oil shale [6]. The spectra were retrieved using as-received oil shale sample. In addition to characteristic bands and peaks corresponding to the organic matter, apparent bands and strong, high-intensity peaks for functional groups were recorded (Fig. 3), such as those for phenolic and carboxylic hydroxyls, carboxyl and carbonyl groups. Despite evidence of the rich organic character, significant functional bands corresponding to hydroxyl, carboxyl and carbonyl groups in this typical spectrum point to a highly humic nature. The high -OH band at $3422 \mathrm{~cm}^{-1}$ as well as strong forms of carboxyl and carbonyl bands correspond to a humic character, even higher than low-rank, immature lignites $[7,8]$. The oxygen-rich hydroxyl, carboxyl and carbonyl functionals are polar in nature. The remarkable presence of these polar functionals imposes a hydrophillic nature to oil shale particles during flotation [9], and this is similar to the poor floatability of low-rank lignites. These findings suggest that anticipating a hydrophillic behavior, even for high quality oil shales with good organic content, is a perception and high wettability of oil shale particles due to the polar surface behavior. 


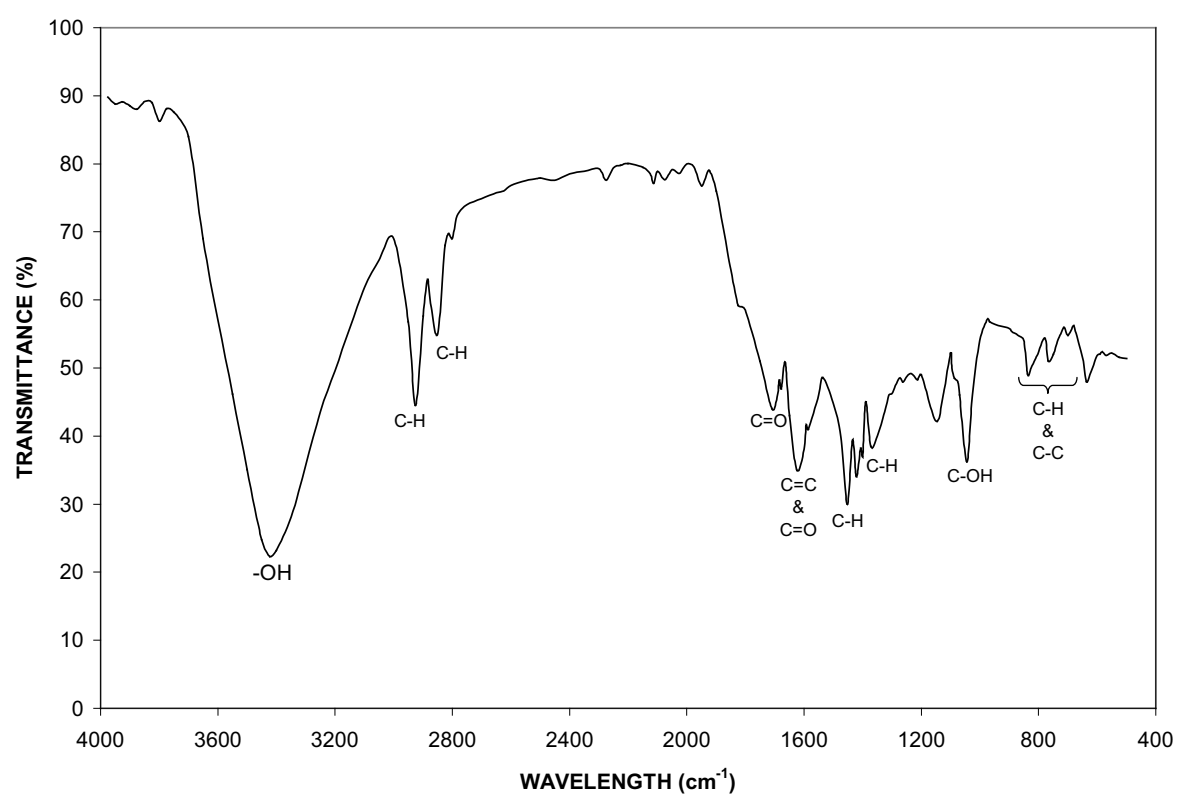

Figure 3. FTIR spectrum of a high-quality oil shale [6].

\section{Issues related to post-grinding surface characteristics}

Besides the hydrophillic behavior of oil shale particles in the flotation pulp, the release of organic matter in relatively liquid form, is an important difficulty in flotation based oil shale cleaning. This difficulty corresponds to the incidental, i.e. undesired and uncontrolled release of bitumen as the grind size becomes finer and subsequent coating of particles, regardless of either inorganic or organic, by this bitumen film [6]. The bitumen film is organic. The thin film around inorganic/organic entities caused by the smearing of released bitumen may significantly interfere with the selectivity of flotation, since this film randomly renders inorganic/organic particles hydrophobic. This non-selective hydrophobic behavior will eventually result in flotation of inorganic entities along with organic ones, imparting separation between the ash making and organic-rich constituents.

Fine grinding is inevitable and acts as a preparatory step for downstream processes, aiming at the disintegration of the organic and inorganic constituents prior to flotation cleaning of solid fossil fuels. Figure 4 demonstrates the impact of incidental release of bitumen during grinding of oil shales on the surface characteristics of oil shale particles [6]. With increasing fineness from the raw sample down to $-25 \mu \mathrm{m}$, the characteristic bands and peaks corresponding to the organic content of the oil shale became more intense and apparent. The aliphatic $\mathrm{C}-\mathrm{H}$ (due to $\mathrm{CH}_{3}$ and $\mathrm{CH}_{2}$ ) and aromatic $\mathrm{C}-\mathrm{C}$ and $\mathrm{C}=\mathrm{C}$ bands gradually increased intensities, reaching their maximum at $-25 \mu \mathrm{m}$ grind size (Fig. 4 ). The $\mathrm{C}-\mathrm{H}$ bands at 2926 and $2850 \mathrm{~cm}^{-1}$ took a sharper form with increasing fineness. The C-H peak at 2926 $\mathrm{cm}^{-1}$ occurred with a broader form at -50 and $-25 \mu \mathrm{m}$, as compared to coarser sizes. The intensity increase was also recorded for the characteristic C-H peak at $1452 \mathrm{~cm}^{-1}$ and the $\mathrm{C}-\mathrm{H}$ and $\mathrm{C}-\mathrm{C}$ bands at 850 and $675 \mathrm{~cm}^{-1}$, respectively, became stronger as the grind size was made finer. 


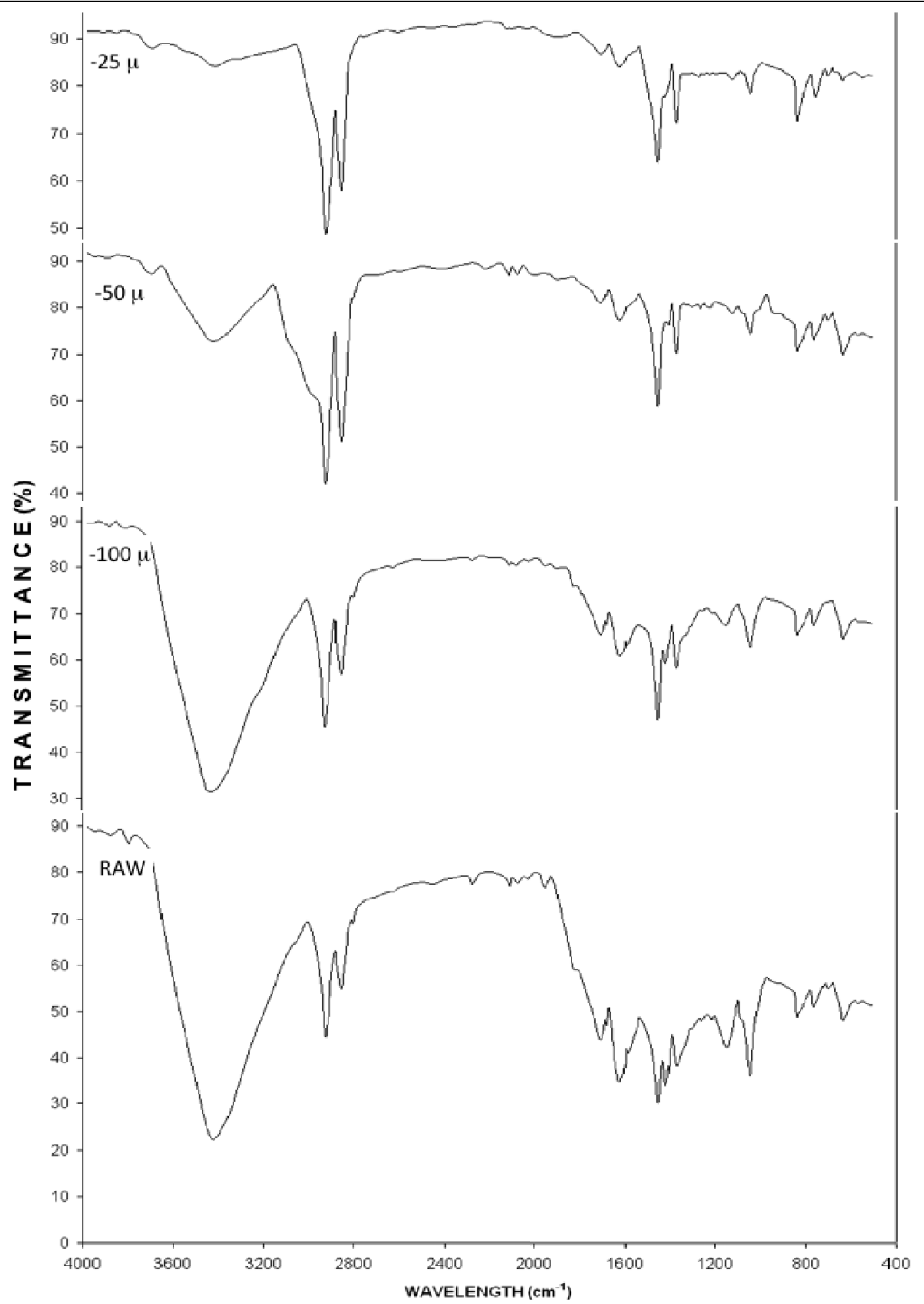

Figure 4. Comparative FTIR spectra of oil shale at different grind sizes [6]. 
Besides significant changes in the forms and intensities of peaks and bands that correspond to the organic matter in oil shales, the peak intensities of the polar functional groups also changed with respect to grind size. The extent of the functional groups relatively decreased with increasing fineness as revealed by the reducing intensities of the $-\mathrm{OH}$ bands of phenolic hydroxyls and $\mathrm{C}=\mathrm{O}$ and $\mathrm{C}-\mathrm{OH}$ peaks of carbonyl and carboxyl groups. The distinctive high-intensity of -OH band at $3422 \mathrm{~cm}^{-1}$ in the spectrum of the raw oil shale took a very slight form in the $-25 \mu \mathrm{m}$ sample (Fig. 4). The decreasing intensity of the polar functional groups and the increasing intensities of the peaks of organic groups showed that the oil shale particle surfaces became dominated by the organic matter with increasing fineness. The release of bitumen with fine-grinding of oil shale and coating of oil shale particles nonselectively by an organic film was also demonstrated by the XPS analysis of the surface of oil shale particles, as presented in Table 1 [6].

The presented data suggest and confirm that the humic character of oil shale particle surfaces changed to an organic-dominant form in prolonged grinding periods. This change corresponds to the shift of the natural hydrophilicity of oil shale particles to the hydrophobic behavior. Yet, this change does not present an advantage with respect to rejection of ash making and polluting constituents through flotation, because this hydrophobic behavior, as imposed by the uncontrolled release of bitumen, is non-selective, and randomly applies to any particle during the grinding period, as mentioned earlier.

Table 1. Surface characteristics of oil shale particles with respect to grind size [6].

\begin{tabular}{|c|c|c|c|c|c|c|c|c|c|c|c|}
\hline \multirow{2}{*}{$\begin{array}{c}\text { Grind } \\
\text { size } \\
(\mu \mathrm{m})\end{array}$} & \multicolumn{6}{|c|}{ Elemental composition (\%) } & \multicolumn{5}{|c|}{ Carbon functionalities (\%) } \\
\hline & $\mathbf{C}$ & $\mathbf{O}$ & $\mathbf{C a}$ & Mg & $\mathbf{S i}$ & $\mathbf{F e}$ & C-H & C-C & $\mathbf{C}=\mathbf{C}$ & $\mathbf{C}=\mathbf{O}$ & $\mathrm{C}-\mathrm{OH}$ \\
\hline-200 & 30.60 & 23.88 & 21.78 & 13.56 & 3.76 & 5.74 & 18.22 & 13.94 & 10.52 & 44.32 & 12.92 \\
\hline-100 & 34.36 & 22.45 & 20.98 & 12.89 & 3.45 & 5.17 & 19.56 & 14.52 & 11.00 & 42.8 & 12.02 \\
\hline-50 & 54.98 & 16.88 & 14.78 & 8.46 & 1.52 & 2.92 & 30.98 & 21.65 & 15.28 & 23.89 & 8.14 \\
\hline-25 & 64.90 & 14.58 & 11.42 & 5.68 & 1.02 & 1.68 & 34.07 & 23.98 & 16.37 & 18.94 & 6.56 \\
\hline
\end{tabular}

\section{Conclusions}

Previous work show that cleaning of oil shales through flotation is not a straight forward process. Behavior of oil shale particles in the flotation pulp is determined by oxygen-rich polar surface functionals, that impose natural hydrophillicity to oil shale particles. Remarkable extent of inorganic minerals, such as carbonates, is another negative aspect, that may keep the efficiency and effectiveness of flotation cleaning limited. This is due to interference and smearing of inorganic particles with/on organic entities, dilution of low-ash concentrate due to in-bubble entrapment/inocculation of fine inorganics. Another major issue regarding the surface behavior is the uncontrolled release of organic matter during grinding of oil shale. It is likely that release of organic matter results in randomly coating of oil shale particles by an organic film, particularly as the grind size is made finer. This smearing effect eventually results in the loss of selectivity, which in turn, may reduce the separation possibility between organic and inorganic entities. It is therefore suggested that the grind size should be carefully decided, grinding should be strictly controlled and over-grinding should be avoided in preparing oil shales for flotation cleaning.

\section{References}

1. T.F. Yen, G.V. Chilingarian, Oil Shale (Elsevier, Amsterdam, 1976)

2. B.P. Tissot, D.H. Welte, Petroleum Formation and Occurrence (Springer Verlag, Germany, 1984)

3. E. Vali, I. Valgma, E. Reinsalu, Oil Shale, 25(2S), 101 (2008) 
4. N.E. Altun, C. Hicyilmaz, J.-Y. Hwang, A.S Bagci, Energ. Fuel., 20 (2006)

5. N.E. Altun, C. Hicyilmaz, J.-Y. Hwang, A.S. Bagci, Fuel Process. Technol., 87, 783 (2006)

6. $\quad$ N.E. Altun, Oil Shale 26 (3), 382 (2009)

7. A.F. Gaines, The Infrared Spectra of Coals (NATO ASI Series C, Kluwer Academic Publishers, Dordrecht, 1988)

8. D.W. Van Krevelen, Coal, 3rd edn. (Elsevier, Amsterdam, 1993)

9. G. Atesok, M.S. Celik, Fuel, 79, 1509 (2000) 